\title{
Vasculitides associated with IgG antineutrophil cytoplasmic autoantibodies in childhood
}

\author{
Federica Vanoni • Alberto Bettinelli • Franco Keller • \\ Mario G. Bianchetti • Giacomo D. Simonetti
}

Received: 16 February 2009 /Revised: 14 June 2009 / Accepted: 15 June 2009 /Published online: 30 July 2009

(C) IPNA 2009

\begin{abstract}
Immunoglobulin (Ig)G antineutrophil cytoplasmic autoantibodies are causally associated with necrotizing vasculitides that are characterized immunopathologically by little or no deposition of immunoreactants, such as Wegener granulomatosis, microscopic polyangiitis, Churg-Strauss angiitis, "renal-limited" vasculitis and a number of druginduced vasculitides. Clinical routine testing targets the antigens myeloperoxidase and proteinase 3 . However, in all of the conditions mentioned, the renal histopathologic
\end{abstract}

F. Vanoni · M. G. Bianchetti

Department of Pediatrics, Bellinzona and Mendrisio Hospitals, University of Bern,

Bern, Switzerland

A. Bettinelli

Department of Pediatrics, San Leopoldo Mandic Hospital,

Merate-Lecco, Italy

F. Keller

Clinical Immunology Laboratory Medicine,

Ticino Cantonal Hospital,

Bellinzona, Switzerland

G. D. Simonetti

Pediatric Nephrology,

University Children's Hospital Bern and University of Bern,

Bern, Switzerland

\section{G. D. Simonetti}

Pediatric Nephrology,

Center for Children and Adolescent Medicine,

University of Heidelberg,

Heidelberg, Germany

M. G. Bianchetti $(\bowtie)$

San Giovanni Hospital, 6500 Bellinzona, Switzerland

e-mail: mario.bianchetti@pediatrician.ch findings are indistinguishable. Churg-Strauss angiitis (characterized by necrotizing vasculitis, granulomatous inflammation and tissue eosinophilia), Wegener granulomatosis (characterized by necrotizing vasculitis and granulomatous inflammation) and microscopic polyangiitis (characterized by necrotizing vasculitis) often present with fever, weight loss and a multisystem involvement (ear, nose, throat, lung, eyes, peripheral nerve and heart). Fifty years ago these conditions were very often fatal within 6 months of diagnosis. The introduction of corticosteroids and cyclophosphamide has resulted in a dramatic clinical benefit. Patients who develop treatment-related morbidity can be switched from cyclophosphamide to azathioprine after achieving remission. In patients with less severe disease, methotrexate achieves remission with a success rate similar to that of cyclophosphamide. Plasma exchange, in association with immunosuppression, is likely to be a beneficial therapy for patients with severe kidney disease or pulmonary hemorrhage.

Keywords Churg-Strauss angiitis .

Drug-induced vasculitis · Microscopic polyangiitis ·

Renal-limited vasculitis $\cdot$ Review $\cdot$ Wegener granulomatosis

\section{Introduction}

An aberrant interaction between neutrophils and vascular endothelial cells underlies the development of necrotizing vasculitides that are characterized by little or no deposition of immunoreactants, such as immunoglobulin (Ig)A, IgM, IgG and complement components. This distinct group of disorders includes Wegener granulomatosis, microscopic polyangiitis, Churg-Strauss angiitis and a number of drug- 
induced vasculitides [1-3]. Necrotizing vasculitides in both children and adults are associated with circulating $\operatorname{IgG}$ antineutrophil cytoplasmic autoantibodies (ANCA) [1-3].

Recent data indicate that IgG ANCA are directly involved in the pathogenesis of vascular injury: in susceptible individuals, infections with fimbriated bacteria trigger Wegener granulomatosis, microscopic polyangiitis, "renal limited vasculitis" and Churg-Strauss angiitis by inducing the production of antibodies to a human protein expressed on neutrophils, the lysosomal membrane protein2. These antibodies activate neutrophils which, in turn, may erode the vasculature [4].

In this review article we focus on the presentation and the management of children with ANCA-positive vasculitides. The classification criteria for a number of pediatric vasculitides developed by the European League against Rheumatism and the Pediatric Rheumatology European Society will be used [5].

\section{Antineutrophil cytoplasmic autoantibodies testing}

The antigens targeted during clinical routine testing of IgG ANCA are myeloperoxidase and proteinase 3, which are located in the azurophilic granules of neutrophils and the peroxidase-positive lysosomes of monocytes. Two major immunofluorescence patterns occur (Fig. 1). (1) The perinuclear or "P-ANCA" pattern results from a staining pattern around the nucleus, with the antibody responsible for this pattern usually directed against myeloperoxidase (and only occasionally proteinase 3). (2) The cytoplasmic or "C-ANCA" pattern is characterized by a diffuse staining throughout the cytoplasm; in most cases, antibodies directed against proteinase 3 cause this pattern, but myeloperoxidase can occasionally be responsible $[6,7]$.

In some patients with connective tissue disorders, chronic inflammatory bowel disease and autoimmune hepatitis, an atypical ANCA pattern that may be confused with "P-ANCA" patterns are sometimes observed. "PANCA" are common in patients with cystic fibrosis, particularly those patients with severe bacterial airway infections. In this case, they are directed against the bactericidal permeability increasing protein, a factor of the innate defense repertoire against Gram-negative bacteria $[6,7]$.

The indirect immunofluorescence assay, which remains non-standardized, is sensitive but not highly specific, while the enzyme-linked immunosorbent assay (ELISA), which is performed using purified specific antigens, is more specific. Consequently, the currently recommended approach is to screen for ANCA using immunofluorescence assays and to confirm positive results with ELISA in order to determine the specific antibody $[6,7]$.
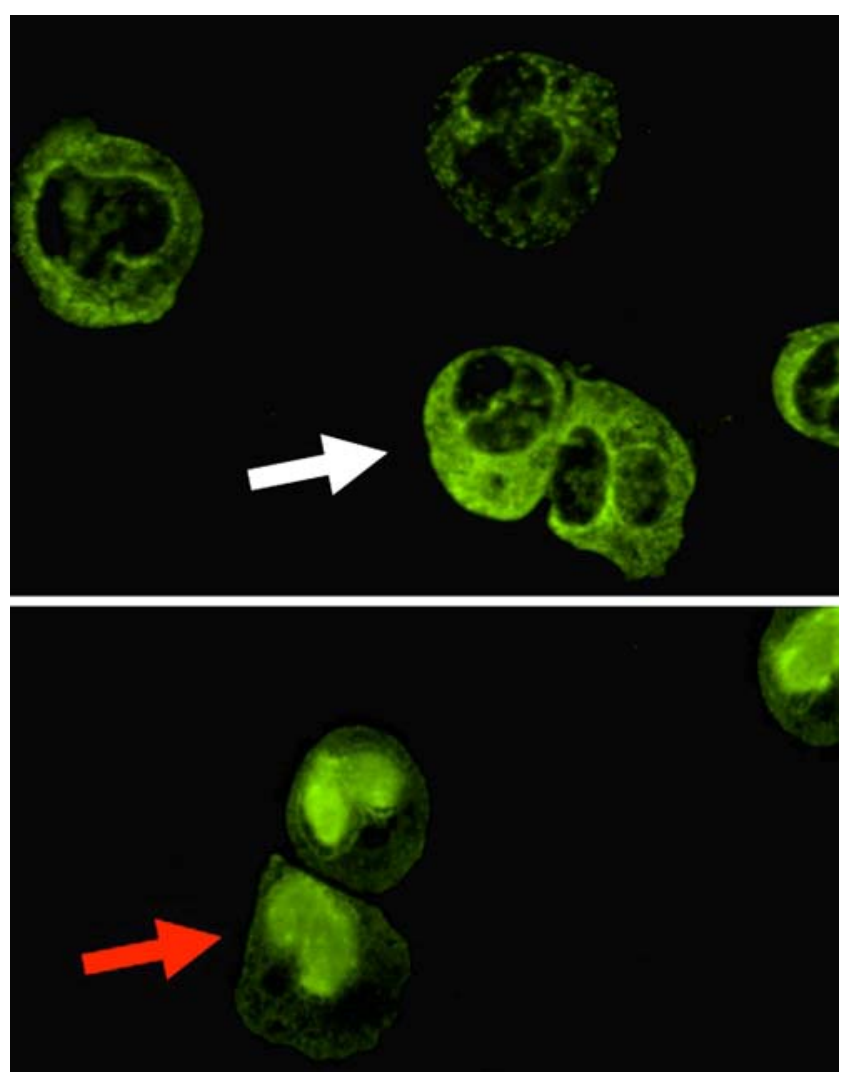

Fig. 1 Testing for antineutrophil cytoplasmic autoantibodies (ANCA) by indirect immunofluorescence using ethanol-fixed neutrophil substrates. The upper panel reveals a diffuse granular cytoplasmic staining pattern, characteristic of cytoplasmic ANCA $(C-A N C A)$. The lower panel reveals a homogenous perinuclear staining pattern, which is characteristic for perinuclear autoantibodies $(P-A N C A)$

Because of the common difficulty in distinguishing the P-ANCA pattern of immunofluorescence from that caused by antinuclear antibodies, individuals with antinuclear antibodies often have "false-positive" results based on ANCA testing by immunofluorescence. Rigorous immunofluorescence testing procedures for ANCA include the use of both ethanol- and formalin-fixed neutrophil substrates primarily because formalin-fixed neutrophils prevent the rearrangement of charged cellular components around the nucleus. The use of both cell substrates enables antibodies causing a "true" P-ANCA pattern to be distinguished from those directed against the nuclear antigens $[6,7]$.

As stated above, ANCA are associated with many cases of Wegener granulomatosis, microscopic periarteritis, Churg-Strauss angiitis, "renal-limited" vasculitis and some drug-induced vasculitides (Table 1). Under these conditions, ANCA have specificities for either proteinase 3 or myeloperoxidase, but almost never for both. 
Table 1 Features in pediatric patients with Wegener granulomatosis, microscopic polyangiitis and Churg-Strauss angiitis

\begin{tabular}{|c|c|c|c|}
\hline Feature & Wegener granulomatosis & Microscopic polyangiitis & Chrurg-Straus angiitis \\
\hline $\begin{array}{l}\mathrm{IgG} / \mathrm{ANCA} \\
\text { positivity }\end{array}$ & $90 \%$ & $70 \%$ & $\leq 50 \%$ \\
\hline Antigen & Proteinase $3^{\mathrm{a}}$ & $\begin{array}{l}\text { Myeloperoxidase }> \\
\text { proteinase } 3\end{array}$ & Myeloperoxidase $>$ proteinase 3 \\
\hline $\begin{array}{l}\text { Peripheral } \\
\text { eosinophilia }\end{array}$ & Rather rare (and mild) & - & Very often (and severe) \\
\hline Histology & Necrotizing vasculitis-granulomatous inflammation & $\begin{array}{l}\text { Necrotizing vasculitis-no } \\
\text { granulomatous } \\
\text { inflammation }\end{array}$ & $\begin{array}{l}\text { Necrotizing vasculitis-- } \\
\text { granulomatous inflammation-- } \\
\text { tissue eosinophilia }\end{array}$ \\
\hline $\begin{array}{l}\text { Fever, } \\
\text { weight loss }\end{array}$ & Very often & Very often & Very often \\
\hline $\begin{array}{l}\text { Ear, nose, } \\
\text { throat }\end{array}$ & $\begin{array}{l}\text { Sinusitis, saddle nose, epistaxis, oral or nasal ulcers, otitis, } \\
\text { conductive hearing loss, subglottic stenosis }\end{array}$ & Absent or mild & $\begin{array}{l}\text { Nasal polyps, allergic rhinitis, } \\
\text { conductive hearing loss }\end{array}$ \\
\hline Lung & $\begin{array}{l}\text { Nodules, infiltrates, cavitary lesions, rarely alveolar } \\
\text { hemorrhage }\end{array}$ & Alveolar hemorrhage & $\begin{array}{l}\text { Asthma, nonfixed infiltrates, rarely } \\
\text { alveolar hemorrhage }\end{array}$ \\
\hline Kidney & $\begin{array}{l}\text { Segmental necrotizing glomerulonephritis (granulomatous } \\
\text { inflammation rarely seen in biopsy specimens) }\end{array}$ & $\begin{array}{l}\text { Segmental necrotizing } \\
\text { glomerulonephritis }\end{array}$ & $\begin{array}{l}\text { Segmental necrotizing } \\
\text { glomerulonephritis }\end{array}$ \\
\hline Eye & $\begin{array}{l}\text { Conjunctivitis, (epi)scleritis, orbital inflammatory disease, } \\
\text { uveitis }\end{array}$ & $\begin{array}{l}\text { Occasionally (epi)scleritis, } \\
\text { uveitis }\end{array}$ & Occasionally (epi)scleritis, uveitis \\
\hline $\begin{array}{l}\text { Peripheral } \\
\text { nerve }\end{array}$ & Occasionally vasculitic neuropathy & Often vasculitic neuropathy & Often vasculitic neuropathy \\
\hline Heart & Occasionally valvular lesions & Rare & $\begin{array}{l}\text { Often cardiomyopathy, pericardial } \\
\text { effusion or valvular lesions }\end{array}$ \\
\hline
\end{tabular}

Ig, Immunoglobulin; ANCA, antineutrophil cytoplasmic autoantibodies

${ }^{\mathrm{a}}$ Very rarely myeloperoxidase

\section{Wegener granulomatosis}

Approximately $90 \%$ of patients with active, generalized Wegener granulomatosis are ANCA-positive (in $80-90 \%$ of these, the antibodies are directed against proteinase 3 ; in the remaining patients, the ANCA-positive antibodies are directed against myeloperoxidase). ANCA-negative patients with active disease mostly suffer from a limited form of the disease. Thus, the absence of ANCA clearly does not exclude the diagnosis of Wegener granulomatosis $[6,7]$.

Microscopic polyangiitis (and renal-limited vasculitis)

Approximately $70 \%$ of the patients with microscopic polyangiitis and renal limited vasculitis are ANCApositive, with $75-80 \%$ having myeloperoxidase-ANCA [6, 7].

\section{Churg-Strauss angiitis}

Approximately $25-50 \%$ of patients affected with ChurgStrauss angiitis are ANCA positive, with the percentage being somewhat higher in those with active, untreated disease. There is a moderate predilection for myeloperoxidase-ANCA among those patients with Churg-Strauss angiitis who have ANCA $[6,7]$.

ANCA-positive drug-induced vasculitides

Patients with drug-induced ANCA associated vasculitides mostly have myeloperoxidase-ANCA in very high titers. In addition, most also have antibodies to elastase or lactoferrin. Identical testing (including antibodies to elastase or lactoferrin) may also be seen in acute-drug-induced interstitial nephritis $[6,7]$.

\section{Clinical features}

The renal histopathologic findings are indistinguishable in Wegener Granulomatosis, microscopic polyangiitis and renal-limited vasculitis (Fig. 2). Furthermore, some children who present with disease limited to the kidney, i.e. with renal-limited vasculitis, eventually exhibit extrarenal manifestations of either Wegener granulomatosis or microscopic polyangiitis. There is also some overlap between Wegener granulomatosis and microscopic polyangiitis. The distinction between microscopic polyangiitis and Wegener granulomatosis is critical chiefly because Wegener granulomatosis is 


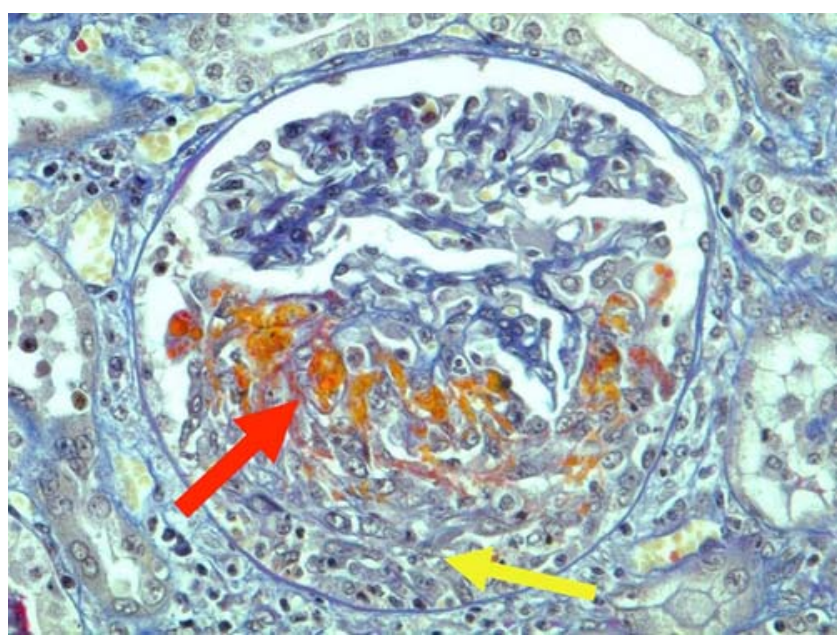

Fig. 2 Characteristic picture of a pauci-immune extracapillary necrotizing glomerulonephritis. The depicted glomerulus contains a segmental fibrinoid necrosis, a cellular crescent and some neutrophil granulocytes (acid fuchsin-Orange G stain). The yellow arrow denotes the cellular crescent, the red arrow the fibrinoid necrosis

substantially more likely to relapse after the achievement of remission and the discontinuation of the drug management.

\section{Wegener granulomatosis}

Wegener granulomatosis is a systemic pauci-immune necrotizing, predominantly small-vessel vasculitis associated with granulomatous inflammation $[5,8]$.

In its "classic form" the condition primarily involves the (upper or lower) respiratory tract and the kidneys. In childhood, the main features at presentation include (1) a female predominance (female-to-male ratio: 4:1), (2) a disease onset most commonly occurring in adolescence and (3) an initial multisystemic presentation with constitutional (fever and weight loss) and respiratory symptoms (Fig. 3) and renal involvement. Most children seek medical advice because of respiratory symptoms. Common and uncommon clinical features in pediatric patients with Wegener granulomatosis are given in Table 2 [9-13].

In addition to a positive proteinase 3 ANCA testing, the most common laboratory abnormalities at presentation are a consistently elevated erythrocyte sedimentation and anemia, which are found in approximately $90-95 \%$ of patients. Less common are altered urinalysis, thrombocytosis, leukocytosis and elevated C-reactive protein, which are found in approximately $50 \%$ of patients [8-13].

The European classification criteria for Wegener granulomatosis require the diagnosis of three of the following six features: (1) abnormal urinalysis; (2) nasal sinus inflammation; (3) subglottic, tracheal or endobronchial stenosis; (4) abnormal chest imaging; (5) positive ANCA testing; (6) granulomatous inflammation on biopsy [5].

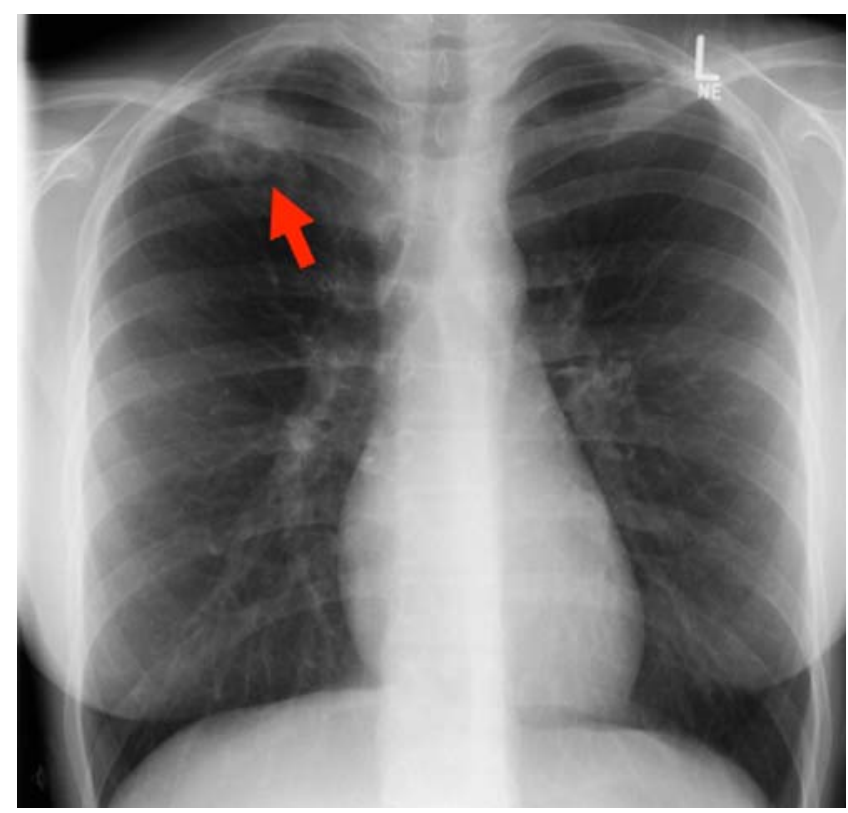

Fig. 3 In this 14-year-old female adolescent with fever, weight loss and moderate cough for 2 months, the chest X-ray discloses (arrow) a nodular lesion in the right upper lobe. The subsequent diagnostic work-up confirmed the working diagnosis of Wegener granulomatosis. The possible diagnosis of tuberculosis was considered, and sputum specimens were submitted to the laboratory for smear and culture

Microscopic polyangiitis (and renal-limited vasculitis)

Microscopic polyangiitis is a pauci-immune necrotizing small vessel vasculitis without clinical or pathological evidence of necrotizing granulomatous disease of the respiratory tract. The condition predominantly ( $80 \%)$ affects the female gender. Approximately $90 \%$ of the patients with microscopic polyangiitis have glomerulonephritis, which is accompanied by a variety of other organ involvement $[5,14-16]$. The distinction between Wegener granulomatosis and microscopic polyangiitis is sometimes difficult to determine [17]. Nasal septal perforation or saddle-nose deformity or thoracic imaging showing nodules or nodular infiltrates that have a tendency to cavitate are usually regarded as typical features of Wegener granulomatosis. Some patients initially present with a vasculitis limited to the kidney [18-20]. However, the great majority of these patients eventually develop extrarenal manifestations of microscopic polyangiitis (more rarely Wegener granulomatosis).

No formal classification criteria for the diagnosis of microscopic polyangiitis in pediatric patients have been proposed by the European League against Rheumatism and the Pediatric Rheumatology European Society [5].

\section{Churg-Strauss angiitis}

The pathologic features of Churg-Strauss angiitis include granulomatosis, vasculitis and eosinophilia [21, 22]. This 
Table 2 Clinical features in pediatric patients with Wegener granulomatosis [9-13]

\begin{tabular}{|c|c|}
\hline Clinical features & Frequency \\
\hline Constitutional symptoms & +++ \\
\hline Fever & +++ \\
\hline Weight loss & +++ \\
\hline Ear, nose throat & +++ \\
\hline Sinusitis & ++ \\
\hline Epistaxis & ++ \\
\hline Oral or nasal ulcers & ++ \\
\hline Otitis, conductive hearing loss & ++ \\
\hline Saddle nose & + \\
\hline Subglottic stenosis & + \\
\hline Pulmonary involvement & +++ \\
\hline Alveolar hemorrhage & ++ \\
\hline Nodule & ++ \\
\hline Non-hemorrhagic alveolar involvement & + \\
\hline Pleural effusion & + \\
\hline Pulmonary embolism & + \\
\hline Renal involvement & +++ \\
\hline Glomerulonephritic urinalysis & +++ \\
\hline Elevated creatinine & ++ \\
\hline Arterial hypertension & + \\
\hline \multicolumn{2}{|l|}{ Ocular involvement } \\
\hline Conjunctivitis, scleritis & $++/+++$ \\
\hline Orbital inflammatory disease & $(+)$ \\
\hline Joint tenderness or swelling & +++ \\
\hline Skin involvement & ++ \\
\hline Purpuric lesions (palpable) & ++ \\
\hline Urticaria & + \\
\hline Panniculitis & + \\
\hline Vascular involvement & ++ \\
\hline Deep vein thrombosis & ++ \\
\hline Pulmonary embolism & ++ \\
\hline Nervous involvement & + \\
\hline
\end{tabular}

,$+++>50 \% ;++, 25-50 \% ;+, 5-25 \% ;(+),<5 \%$

very rare multisystem disorder sometimes develops in asthma patients receiving therapy with a leukotriene antagonist, suggesting that these drugs either cause (or unmask) this angiitis [23]. No pediatric cases of the condition have so far been associated with leukotriene antagonists [24]. A recently performed literature analysis revealed 33 cases of this vasculitis in individuals $\leq 18$ years of age [24]. All children had eosinophilia $\left(>1.510^{9} / \mathrm{L}\right)$ and increased total $\mathrm{IgE}$ levels. At presentation, most children had a history of asthma (more than 90\%) and sinusitis $(80 \%)$. Pulmonary involvement presenting as nonfixed infiltrates was very common (more than $80 \%$ ), whereas pleural effusions were rare (approximately 10\%). Other organs, such as the skin $(70 \%)$, peripheral nerves $(40 \%)$ and the gastrointestinal tract $(40 \%)$ were also frequently involved, while the renal and musculoskeletal systems were conspicuous in only every fifth patient. Cardiac involvement was frequently $(40 \%)$ seen, presenting as cardiomyopathy, pericardial effusions or severe mitral valve regurgitation.

No classification criteria for the diagnosis of ChurgStrauss angiitis in pediatric patients have been proposed by the European League against Rheumatism and the Pediatric Rheumatology European Society [5]. The presence of four of the following six criteria for the diagnosis in a patient with documented vasculitis have been suggested: (1) asthma; (2) eosinophilia on differential white blood cell count; (3) neuropathy; (4) migratory or transient pulmonary opacities detected radiographically; (5) paranasal sinus abnormality; (6) biopsy containing eosinophils in extravascular areas $[21,22]$.

Drug-induced ANCA-positive vasculitides

Patients with drug-induced ANCA-positive vasculitides mostly present with fever, weight loss, joint tenderness and, in particular, cutaneous vasculitis $[25,26]$. However, the full range of clinical features associated with ANCA, including glomerulonephritis and alveolar hemorrhage, can also occur, at least in adults. The implicated agents include medical drugs employed in the treatment of hyperthyroidism (carbimazole, methimazole, propylthiouracil), tumor necrosis factor- $\alpha$ antagonists (including infliximab, etanercept and adalimumab), allopurinol, cefotaxime, clozapine, (di)hydralazine, indomethacin, isoniazid, levamisole [27], minocycline, penicillamine, phenytoin, procainamide and rifampicin. The illicit drug cocaine has also been associated with cutaneous vasculitides. Drug-induced ANCA-positive vasculitides usually resolve with discontinuation of the offending drug, but ANCA levels persist even after active vasculitis has abated.

\section{Management}

\section{Laboratory tests}

Various laboratory tests are used to monitor disease activity, including leukocytosis, thrombocytosis, elevated C-reactive protein and, in particular, erythrocyte sedimentation rate, all of which are relatively nonspecific. In systemic lupus erythematosus, there is a better correlation between erythrocyte sedimentation rate and disease activity than between C-reactive protein level and disease activity. In this condition, C-reactive protein is useful for 
distinguishing between a disease flare and an infection: C-reactive protein usually tends to remain normal or slightly increased in a flare but is elevated in infection, while the erythrocyte sedimentation rate is elevated in both. In ANCA-positive vasculitides, however, there is a limited role for C-reactive protein to distinguish between disease flare and infection.

In ANCA-positive vasculitides, especially Wegener granulomatosis, ANCA titers usually parallel the course of the vasculitis. In particular, the disappearance of ANCA is almost always associated with clinical remission, and patients who maintain negative titers after therapy are at low risk for relapse. A rise in ANCA after remission is predictive of subsequent clinical relapse. However, because of the lack of uniform predictability of clinical relapse, most physicians do not initiate prophylactic therapy on the basis of ANCA level alone. Nonetheless, these patients should be monitored carefully for clinical signs of active disease [28-31].

\section{Drug management}

\section{History}

Fifty years ago Wegener granulomatosis, the most common presentation of ANCA-positive vasculitis, was associated with a patient survival of approximately 6 months after diagnosis. The introduction in the 1960 s of corticosteroids only extended survival by 12 months. This changed radically in the early 1970s with the introduction of cyclophosphamide (in association with prednisone), which resulted in a dramatic clinical benefit. However, many patients developed treatment-related morbidity. It is now known that patients entering remission following induction with cyclophosphamide can be switched to azathioprine, which is less toxic, as maintenance therapy. Furthermore, methorexate achieves remission with a success rate similar to that of cyclophosphamide in less severe forms of the disease $[29,30]$.

\section{Current recommendations for the drug management of disease activity}

ANCA-positive vasculitides are rather rare in children, who are very often excluded from randomized controlled trials. Therefore, the present recommendations are extrapolated from evidence and expert consensus in adults, including a very careful systematic review [29] and the 2009 recommendations of the European Vasculitis Study Group [30]. The management of these vasculitides includes (1) the induction and (2) maintenance of remission, (3) the treatment of relapses and (4) the management of refractory disease.
Wegener granulomatosis (or microscopic polyangiitis)

Disease limited to the upper respiratory tract Owing to its favorable response rates and the favorable adverse-effect profile, cotrimoxazole in a total dosage of approximately $20 \mathrm{mg} / \mathrm{kg}$ twice daily can be used alone or in combination with prednisone to induce and maintain remission when the disease is limited to the upper respiratory tract (localized disease).

Generalized non-organ-threatening disease (= early systemic disease) In patients with a localized (non-renal) disease with constitutional symptoms or a multifocal disease with a nonlife- or nonorgan-threatening prognosis, remission is very often obtained using methotrexate $(0.3 \mathrm{mg} / \mathrm{kg}$ body weight per week orally) plus prednisone $1 \mathrm{mg} / \mathrm{kg}$ per day (instead of the classical but more toxic management with cyclophosphamide plus prednisone). Methotrexate and prednisone are also warranted for the maintenance of remission (unfortunately there is no evidence for the cessation of methotrexate maintenance treatment at 12 months).

Generalized organ-threatening disease (= generalized disease) In Wegener granulomatosis or microscopic polyangiitis presenting with constitutional symptoms and threatened organ function, cyclophosphamide plus prednisone given daily currently remains the gold standard therapy to induced remission. Oral cyclophosphamide ( $2 \mathrm{mg} / \mathrm{kg}$ per day) and intravenous pulsed cyclophosphamide $(15 \mathrm{mg} / \mathrm{kg}$ every $2-3$ weeks) with the same corticosteroid regimen are equally effective for remission induction. The addition of infliximab, a tumor necrosis factor- $\alpha$ antagonist, accelerates the remission by approximately 6 weeks, allowing early tapering of the corticosteroids with a $40 \%$ reduction in the cumulative dose. It is currently recommended to induce remission with intravenous cyclophosphamide $(15 \mathrm{mg} / \mathrm{kg}$ every 2 weeks for 6 months) plus oral prednisone (started at $1.0 \mathrm{mg} / \mathrm{kg}$, tapered to $0.20 \mathrm{mg} / \mathrm{kg}$ by 6 months and maintained at this dose until month 15 , when it should be tapered to 0.15 $\mathrm{mg} / \mathrm{kg}$ maintained for at least 3 more months followed by local practice).

Both azathioprine and methotrexate are used successfully as maintenance therapy for Wegener's granulomatosis, but azathioprine has a better toxicity profile than methotrexate. The combination of azathioprine and prednisone effectively maintains remission (it is assumed that in remission-maintenance one morning dose of prednisone given every second day is as effective but less likely to cause adverse effects than half the dose given every day). Patients who test negative for ANCA benefit most with this regimen, while patients positive for ANCA should be 
closely monitored because they have a higher probability of relapse. When cyclophosphamide is discontinued, azathioprine is started at $2.0 \mathrm{mg} / \mathrm{kg}$ per day (at 6 months it is reduced to $1.5 \mathrm{mg} / \mathrm{kg}$ per day and maintained for at least 6 more months). Mycophenolate mofetil has also been used in open label studies for remission maintenance.

Severe renal disease and immediately life-threatening disease Patients with rapidly progressive kidney disease or with diffuse alveolar hemorrhage have traditionally received a greater immunosuppressive load, such as daily pulses of methylprednisolone and intravenous cyclophosphamide (3-4 mg/kg per day) over brief periods. However, the evidence supporting this practice is scarce. Some studies suggest that plasma exchange [29-32], in association with immunosuppression, is beneficial for patients with moderate to severe chronic kidney disease or pulmonary hemorrhage (plasma exchange is supposedly effective because it removes ANCA).

Refractory disease Various experimental therapies have recently been used for patients not achieving remission with the gold standard treatment. For these patients, intravenous immunoglobulin, which may be effective by interfering with ANCAs binding to their antigens and by inhibiting ANCAs-mediated neutrophil activation, the immunosuppressant mycophenolate mofetil, 15deoxyspergualin, infliximab and rituximab, a monoclonal anti-CD20 IgG1 antibody that induces apoptosis of B lineage cells have been suggested. Although direct comparisons with standard therapies are currently unavailable, there are several reports of patients with refractory disease who have achieved a remission using rituximab despite the failure of standard therapies [33].

\section{Churg-Strauss angiitis}

Most studies of Churg-Strauss syndrome treatment have been performed by the French Vasculitis Study Group. Treatment can be started with prednisone $1 \mathrm{mg} / \mathrm{kg}$ per day, tapering them when the patient improves. In patients with a very severe disease score, cyclophosphamide should be introduced to induce remission, which may be maintained with another less toxic drug [28-30].

\section{Chronic kidney disease}

Chronic kidney disease affects almost all patients with ANCA-positive vasculitides. As in other kidney diseases, the progression towards end-stage kidney disease is to a certain extent due to secondary factors that are unrelated to the activity of the initial disease, including (1) hypertension and (2) pathological proteinuria. Considering the consequences of systemic hypertension in chronic kidney diseases, tight control of blood pressure appears to be crucial. In chronic kidney disease, blocking the reninangiotensin-aldosterone system with converting enzyme inhibitors or with angiotensin II antagonists is superior to a more conventional antihypertensive treatment regimen in preventing progression to end-stage kidney disease. Pathological proteinuria is a further independent mediator of progressive renal function loss that is positively influenced by drugs blocking the renin-angiotensin-aldosterone system. As a consequence, management with a blocker of the renin-angiotensin-aldosterone system is advised in ANCApositive vasculitides with arterial hypertension or overt proteinuria $[34,35]$. During the second and third trimester of pregnancy, however, the use of drugs that block the renin-angiotensin-aldosterone system is strongly cautioned against [36].

Conflict of interest There are no conflicts of interest.

\section{References}

1. Brogan PA (2007) What's new in the aetiopathogenesis of vasculitis? Pediatr Nephrol 22:1083-1094

2. Jennette JC, Falk RJ (2008) New insight into the pathogenesis of vasculitis associated with antineutrophil cytoplasmic autoantibodies. Curr Opin Rheumatol 20:55-60

3. Pusey CD (2006) The continuing challenge of anti-neutrophil cytoplasm antibody-associated systemic vasculitis and glomerulonephritis. J Am Soc Nephrol 17:1221-1223

4. Kallenberg CG, Stegeman CA, Heeringa P (2008) Autoantibodies vex the vasculature. Nat Med 14:1018-1019

5. Ozen S, Ruperto N, Dillon MJ, Bagga A, Barron K, Davin JC, Kawasaki T, Lindsley C, Petty RE, Prieur AM, Ravelli A, Woo P (2006) EULAR/PReS endorsed consensus criteria for the classification of childhood vasculitides. Ann Rheum Dis 65:936-941

6. Savige J, Gillis D, Benson E, Davies D, Esnault V, Falk RJ, Hagen EC, Jayne D, Jennette JC, Paspaliaris B, Pollock W, Pusey C, Savage CO, Silvestrini R, van der Woude F, Wieslander J, Wiik A (1999) International Consensus Statement on testing and reporting of antineutrophil cytoplasmic antibodies (ANCA). Am J Clin Pathol 111:507-513

7. Savige J, Dimech W, Fritzler M, Goeken J, Hagen EC, Jennette JC, McEvoy R, Pusey C, Pollock W, Trevisin M, Wiik A, Wong $\mathrm{R}$, International Group for Consensus Statement on Testing, Reporting of Antineutrophil Cytoplasmic Antibodies (2003) Addendum to the International Consensus Statement on testing and reporting of antineutrophil cytoplasmic antibodies. Quality control guidelines, comments, and recommendations for testing in other autoimmune diseases. Am J Clin Pathol 120:312-318

8. Moosig F, Lamprecht P, Gross WL (2008) Wegener's granulomatosis: the current view. Clin Rev Allergy Immunol 35:19-21

9. Rottem M, Fauci AS, Hallahan CW, Kerr GS, Lebovics R, Leavitt RY, Hoffman GS (1993) Wegener granulomatosis in children and adolescents: clinical presentation and outcome. J Pediatr 122:2631 
10. Laux-End R, Gerber HA, Sauvain MJ, Bianchetti MG (1997) Anti-neutrophil autoantibodies and systemic vasculitis: a report of five cases. Acta Paediatr 86:438-439

11. Stegmayr BG, Gothefors L, Malmer B, Müller Wiefel DE, Nilsson K, Sundelin B (2000) Wegener granulomatosis in children and young adults. A case study of ten patients. Pediatr Nephrol $14: 208-213$

12. Akikusa JD, Schneider R, Harvey EA, Hebert D, Thorner PS, Laxer RM, Silverman ED (2007) Clinical features and outcome of pediatric Wegener's granulomatosis. Arthritis Rheum 57:837-844

13. Belostotsky VM, Shah V, Dillon MJ (2002) Clinical features in 17 paediatric patients with Wegener granulomatosis. Pediatr Nephrol 17:754-761

14. Jennette JC, Thomas DB, Falk RJ (2001) Microscopic polyangiitis (microscopic polyarteritis). Semin Diagn Pathol 18:3-13

15. Jayne D (2008) Challenges in the management of microscopic polyangiitis: past, present and future. Curr Opin Rheumatol 20:3-9

16. Besbas N, Ozen S, Saatci U, Topaloğlu R, Tinaztepe K, Bakkaloglu A (2000) Renal involvement in polyarteritis nodosa: evaluation of 26 Turkish children. Pediatr Nephrol $14: 325-327$

17. von Vigier RO, Trummler SA, Laux-End R, Sauvain MJ, Truttmann AC, Bianchetti MG (2000) Pulmonary renal syndrome in childhood: a report of twenty-one cases and a review of the literature. Pediatr Pulmonol 29:382-388

18. Langford CA, Balow JE (2003) New insights into the immunopathogenesis and treatment of small vessel vasculitis of the kidney. Curr Opin Nephrol Hypertens 12:267-272

19. Booth AD, Pusey CD, Jayne DR (2004) Renal vasculitis - an update in 2004. Nephrol Dial Transplant 19:1964-1968

20. Hattori M, Kurayama H, Koitabashi Y, Japanese Society for Pediatric Nephrology (2001) Antineutrophil cytoplasmic autoantibody-associated glomerulonephritis in children. J Am Soc Nephrol 12:1493-1500

21. Noth I, Strek ME, Leff AR (2003) Churg-Strauss syndrome. Lancet 361:587-594

22. Grau RG (2008) Churg-Strauss syndrome: 2005-2008 update. Curr Rheumatol Rep 10:453-458

23. Beasley R, Bibby S, Weatherall M (2008) Leukotriene receptor antagonist therapy and Churg-Strauss syndrome: culprit or innocent bystander? Thorax 63:847-849

24. Zwerina J, Eger G, Englbrecht M, Manger B, Schett G (2009) Churg-Strauss syndrome in childhood: a systematic literature review and clinical comparison with adult patients. Semin Arthritis Rheum doi:10.1016/j.semarthrit.2008.05.004

25. Wiik A (2008) Drug-induced vasculitis. Curr Opin Rheumatol 20:35-39

26. Gao Y, Zhao MH (2009) Review article: drug-induced antineutrophil cytoplasmic antibody-associated vasculitis. Nephrology (Carlton) 14:33-41

27. Laux-End R, Inaebnit D, Gerber HA, Bianchetti MG (1996) Vasculitis associated with levamisole and circulating autoantibodies. Arch Dis Child 75:355-356

28. Han WK, Choi HK, Roth RM, McCluskey RT, Niles JL (2003) Serial ANCA titers: useful tool for prevention of relapses in ANCA-associated vasculitis. Kidney Int 63:1079-1085

29. Bosch X, Guilabert A, Espinosa G, Mirapeix E (2007) Treatment of antineutrophil cytoplasmic antibody associated vasculitis: a systematic review. JAMA 298:655-669

30. Mukhtyar C, Guillevin L, Cid MC, Dasgupta B, de Groot K, Gross W, Hauser T, Hellmich B, Jayne D, Kallenberg CG, Merkel PA, Raspe H, Salvarani C, Scott DG, Stegeman C, Watts R, Westman K, Witter J, Yazici H, Luqmani R, European Vasculitis Study Group (2009) EULAR recommendations for the management of primary small and medium vessel vasculitis. Ann Rheum Dis 68:310-317

31. Lee RW, D'Cruz DP (2008) Novel therapies for anti-neutrophil cytoplasmic antibody-associated vasculitis. Drugs 68:747-770

32. Savage CO, Sinico RA, Stegeman CA, Westman KW, van der Woude FJ, de Lind van Wijngaarden RA, Pusey CD, European Vasculitis Study Group (2007) Randomized trial of plasma exchange or high-dosage methylprednisolone as adjunctive therapy for severe renal vasculitis. J Am Soc Nephrol 18:2180-2188

33. Walsh M, Jayne D (2009) Targeting the B cell in vasculitis. Pediatr Nephrol 24:1267-1275

34. Simonetti GD, Santoro L, Ferrarini A, Crosazzo-Franscini L, Fossali E, Bianchetti MG, CHILD Project (2007) Systemic hypertension and proteinuria in childhood chronic renal parenchymal disease: role of antihypertensive drug management. Paediatr Drugs 9:413-418

35. Hadtstein C, Schaefer F (2008) Hypertension in children with chronic kidney disease: pathophysiology and management. Pediatr Nephrol 23:363-371

36. Quan A (2006) Fetopathy associated with exposure to angiotensin converting enzyme inhibitors and angiotensin receptor antagonists. Early Hum Dev 82:23-28 